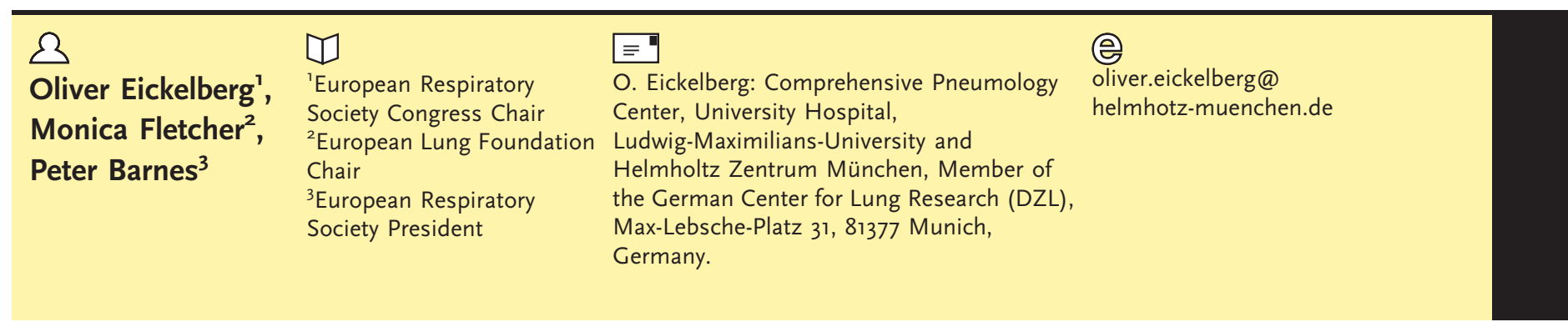

\title{
Healthy Lungs for Life campaign: a festival of lung health for the ERS International Congress, Munich and the globe
}

The European Respiratory Society (ERS) will hold its annual International Congress this year in Munich, Germany. The ERS congress has been growing and evolving over the last 10 years, with attendance soaring to a steady 20000 . The congress is home to all stakeholders in respiratory medicine including researchers, clinicians, allied professionals and industy. More recently, working together with the European Lung Foundation (ELF), patients and policy makers have started to attend the congress and play a key role in discussions and activities. Each year the ERS congress is becoming more diverse and more relevant to all key players in the field, but clearly it has limitations as in order to attend the congress people have to travel, which is not always possible. With this in mind, in 2014, we want to make sure that the ERS congress, and all of us who take part in it, will have a bigger impact than previously realised, not just on those attending the ERS congress, but to a truly global audience.

\section{The big idea}

Figures from the latest edition of the European Lung White Book [1] give the startling message that one in eight Europeans currently die from a lung condition. Lung diseases, over the past two decades, have been a globally important cause of death and disability, and are set to remain as such. However the nature of lung disease is set to change from a situation where the highest proportion of deaths occur from those with infectious lung diseases to a situation where people are living with longterm conditions, such as asthma and chronic obstructive pulmonary disease (COPD). This brings with it the challenges of how to manage and care for these people who are living with their conditions for the next 2030 years. To address this, the "Healthy Lungs for Life" initiative will be launched in 2014. The concept behind this initiative is to develop a long-term health awareness campaign that will speak not only to those already affected by lung disease, in order to improve their quality of life, but also to those who may be affected in the future. The objective is to focus on prevention and public education, to try and reduce the burden of lung disease on society, and to use the ERS congress as the driving force behind the campaign.
Statement of Interest None declared. 

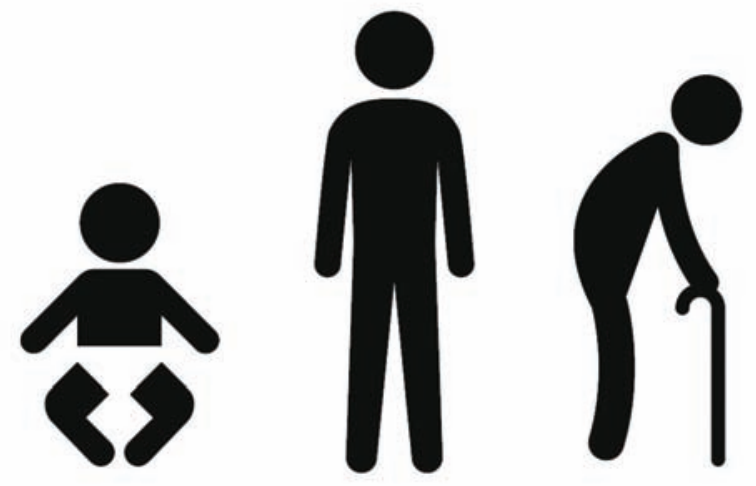

\section{Air pollution affects $100 \%$ of the population from unborn babies to the very elderly}

\section{The topic}

A theme will be selected each year under the umbrella of Healthy Lungs for Life on which all activities will be focused, in order to communicate a wide range of key messages over the coming years. This year, in 2014, the theme for Healthy Lungs for Life will be Clean Air. The air that we breathe each day has a massive impact on our lungs, the first internal organ it comes in contact with. Clean air means air free from particulate

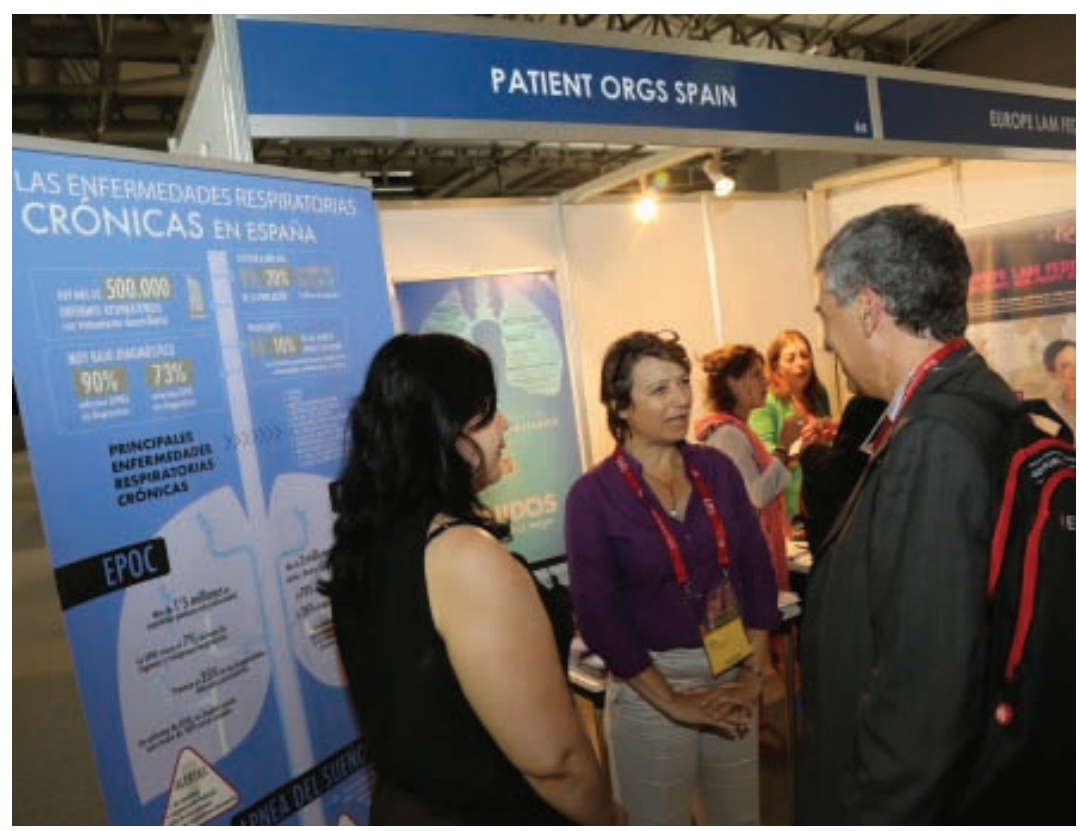

matter, pathogens, smoke and dangerous gases. We all have little control over the air that we breathe, but learning more about the quality of air and its impact can help people to find the best way to protect themselves.

\section{The activities}

So, the theme is set and the message is clear but how will we achieve our goals. A range of activities and events will be held in Munich in the run up to and during the ERS congress, which is being held from the 6th-10th September 2014. These events will be held at the congress venue and in the city itself. Each of the events will target one or more of the respiratory stakeholders.

First, we will communicate the key figures and findings from the recent European Lung White Book via an impactful set of media materials that will speak to young and old alike. This will include bill boards, posters and videos across the city of Munich in as many public places that we can gain access to.

For the ERS International Congress itself, we will put together a 20-point plan to make the congress greener, organise a range of symposia that focus on air and lung health, and film the symposia so that they can be transmitted to audiences in other countries. Media and press activities will focus on clean air, as will the opening ceremony and the ELF/ ERS awards.

In the city, we will take part in an event that will be focussed on the children of Munich, encouraging them to think about the health of their lungs, and how they can protect them. We will be taking over the city of Munich to set up an exhibition about lung health and clean air, whilst offering the chance for all members of the public to have their lung function tested. In addition we will hold sessions for patients and the public to meet members of the ERS to learn about their conditions.

Finally, all of the factsheets, posters and promotional items produced for all the activities will be modified and translated in order to allow people to recreate events across the globe during September. This roll out of Healthy Lungs for Life will incorporate the 3rd World Spirometry Day (WSD) and 
we will try and beat our previous record of 760 events held in over 80 countries. A website is being launched in March 2014 in order to act as a one-stop point of reference for all Healthy Lungs for Life activities. Please visit www.healthylungsforlife.org in order to find out more about what is happening in Munich and how you can work together with us to have an impact in your home community.

\section{The partnership}

This initiative is being spearheaded by the ERS and ELF, but it will be a partnership between both organisations and the Forum of European Respiratory Societies (FERS), the Forum of International Respiratory Societies (FIRS), all the patient organisations working with ELF, the Deutscher Lungentag, Munich city, the Messe Munich Congress centre, and other nongovernmental organisations working in the field of clean air. Key to the success of the initiative is the strong partnership with the medical industry, which will be coming together to financially support the initiative in a novel and unique way, as well as holding their own events under the Healthy Lungs for Life umbrella.

\section{The impact}

The success of the Healthy Lungs for Life initiative will provide a platform to deliver lung health messages and raise awareness of risk factors for lung disease. By pulling together key partners, we will create a highvisibility campaign involving respected leaders in the field that will have an impact never seen before in the field of respiratory medicine. We invite all of you to get involved with this ambitious project. By working together we can work to reduce the burden of lung disease and improve the lives of those it affects.

\section{References}

1. Gibson GJ, Loddenkemper R, Sibille Y, et al. European Lung White Book. Sheffield, European Respiratory Society, 2013. 